Article

\title{
An Equivalent Circuit of Longitudinal Vibration for a Piezoelectric Structure with Losses
}

\author{
Tao Yuan *, Chaodong Li and Pingqing Fan \\ School of Mechatronic Engineering and Automation, Shanghai University, Shanghai 200072, China; \\ cdli@staff.shu.edu.cn (C.L.); fanpingqing@163.com (P.F.) \\ * Correspondence: taoyuan2016@gmail.com
}

Received: 2 February 2018; Accepted: 20 March 2018; Published: 22 March 2018

\begin{abstract}
Equivalent circuits of piezoelectric structures such as bimorphs and unimorphs conventionally focus on the bending vibration modes. However, the longitudinal vibration modes are rarely considered even though they also play a remarkable role in piezoelectric devices. Losses, especially elastic loss in the metal substrate, are also generally neglected, which leads to discrepancies compared with experiments. In this paper, a novel equivalent circuit with four kinds of losses is proposed for a beamlike piezoelectric structure under the longitudinal vibration mode. This structure consists of a slender beam as the metal substrate, and a piezoelectric patch which covers a partial length of the beam. In this approach, first, complex numbers are used to deal with four kinds of losses-elastic loss in the metal substrate, and piezoelectric, dielectric, and elastic losses in the piezoelectric patch. Next in this approach, based on Mason's model, a new equivalent circuit is developed. Using MATLAB, impedance curves of this structure are simulated by the equivalent circuit method. Experiments are conducted and good agreements are revealed between experiments and equivalent circuit results. It is indicated that the introduction of four losses in an equivalent circuit can increase the result accuracy considerably.
\end{abstract}

Keywords: equivalent circuit; piezoelectric structure; loss; longitudinal vibration; impedance

\section{Introduction}

Piezoelectric structures such as bimorphs and unimorphs are of great research interest for a wide variety of applications including ultrasonic motors [1], microgrippers [2], and microcantilever biosensors [3]. Impedance or admittance curves play a remarkable role in the study of piezoelectric structures, and electromechanical properties like resonance frequency, antiresonance frequency, quality factor, and losses are revealed in those curves. Various methods are used to obtain the impedance and admittance curves theoretically. The typical one is Finite Element Analysis (FEA) which mainly relies on FEA software like ANSYS and ABAQUS, but the software is expensive and losses in piezoelectric materials are ignored. The other method is by way of a Mason equivalent circuits model. The equivalent circuit separates the piezoelectric structure into an electrical port and two acoustic ports through the use of an ideal electromechanical transformer [4]. It contains information derived from the mathematical statement of the structure, such as the piezoelectric constitutive equation and the motion equation [5], and gives much faster calculation compared with FEA [6]. Moreover, Mason's model only uses one-dimensional assumptions and a more accurate result can be obtained [7]. Therefore, it is more suitable to use equivalent circuits to present the electromechanical behavior of piezoelectric structures.

Mason's equivalent circuit of piezoelectric structures has been investigated extensively since its introduction. Mason developed the Butterworth-Van Dyke (BVD) equivalent circuit from a one-port model into a three-port model by considering not only the electrical terminal but also the mechanical terminal of the piezoelectric patch [8]. Germano [9] used a simplified Mason's equivalent circuit to 
describe the electromechanical and electroacoustic behaviors of a bimorph. Bao et al. [10] studied the thickness mode of a bilaminar actuator. Yang et al. [11] modeled a piezoelectric energy harvester composed of a rectangular unimorph. Wang et al. [12] simulated a bimorph piezoelectric energy harvester with segmented electrodes. The above studies focus on the bending vibration modes of piezoelectric patches and related metal substrates; thus, the motion equations which generate the equivalent circuits are of flexure vibrations of the structures, and do not take the longitudinal vibration modes into consideration because longitudinal vibrations are not the working condition of those bimorphs and unimorphs. Nevertheless, for some particular applications, such as multimode ultrasonic motors, the longitudinal vibration modes of piezoelectric patches play a remarkable role [13-17]. For those ultrasonic motors, first-order longitudinal vibration is used together with second- or fourth-order bending vibration to generate an elliptical motion locus at the drive feet. Except for the study of magnetoelectric laminated composites by Dong et al. [18,19], little attention has been drawn to the longitudinal vibration modes of piezoelectric structures.

Another aspect paid little attention is the loss of metal substrates in piezoelectric structures. Loss mechanisms of piezoelectric materials have been investigated for a long time and plenty of studies have been conducted. Holland and Uchino extensively described the losses in piezoelectric materials, and found that there are three losses: dielectric, elastic, and piezoelectric losses [20,21]. Sherrit et al. [22] compared the KLM (Krimholtz, Leedom, and Matthae) and Mason's equivalent circuits including the three losses. Chen et al. [23] established an equivalent circuit composed of complex material numbers which represent the three losses. Dong et al. [24] developed Mason's equivalent circuits with three losses and external loads for different configurations of electrodes. Among those studies, "pure" piezoelectric ceramics are the targets when the equivalent circuits are related with losses and no metal substrates are concerned. This approach simplifies the derivation of motion equations, while for practical applications, the metal substrates are included. Therefore, it is more accurate to take the whole structure as a "composite" when investigating the properties of piezoelectric structures. In addition, since the metal substrates account for large portions of the entire structures, the elastic losses of the metal substrate should not be neglected while the losses in the piezoelectric ceramics are involved.

The aim of this paper is to establish an equivalent circuit for a beamlike piezoelectric structure in longitudinal vibration mode. In the motion equation, elastic loss in the metal substrate and three losses in the piezoelectric patch are built into the related parameters, and the longitudinal vibration mode is dealt with. Based on the equation, an equivalent circuit with four kinds of losses is derived. Using MATLAB, the impedance curve of the structure is obtained by calculating the equivalent circuit. Finally, the effectiveness of the equivalent circuit considering both elastic loss of the metal substrate and the three piezoelectric material losses is verified through experiments.

\section{Loss and Motion Equation of the Piezoelectric Structure}

Figure 1 shows the configuration of the piezoelectric structure, which consists a slender beam (metal substrate, the length/thickness ratio is 15.9) made of aluminum and a piezoelectric patch (PZT). The whole structure divides into four parts; Sections 0-2 represent the metal substrate. $\mathrm{L}_{0}$ and $\mathrm{L}_{1}$ denote the lengths of related sections in Cartesian coordinates. The nomenclature used in this paper is summarized in Appendix B. 


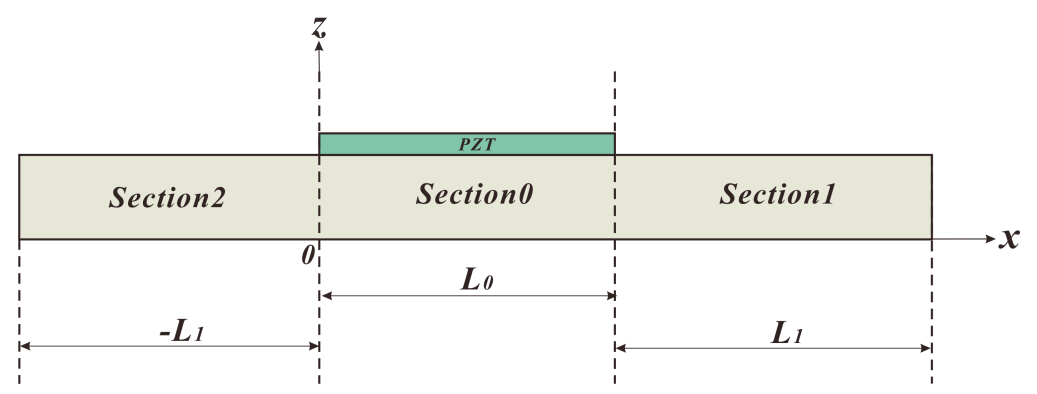

Figure 1. Piezoelectric structure consisting of a slender beam and a piezoelectric patch (PZT).

Damping, which is responsible for dissipation of energy, is one of the key properties that determines the dynamic responses of structures [25]. Damping from the oscillatory system results in the decay of amplitude of free vibration [26]. Losses expressed in complex numbers are among the most suitable indices for describing damping [27]. In this paper, we apply the superscript " $" *$ " to indicate the complex number parameters of the metal substrate and PZT. It should be noted that the superscript "*" differs from the complex conjugate. For the metal substrate, we use aluminum, and the complex Young's modulus is defined to describe the properties of aluminum.

$$
Y_{M}^{*}=Y_{M}\left(1+j \tan \phi_{M}\right)
$$

where $Y_{M}^{*}$ is the complex Young's modulus of aluminum, $Y_{M}$ is the Young's modulus, $j$ is the imaginary notation, and $\tan \phi_{M}$ is the loss factor of aluminum, where the subscript " $M$ " indicates the metal substrate (aluminum).

For piezoelectric materials, heat generation due to losses leads to the degradation of material properties; losses are a major concern for miniaturized devices with high power density. Loss in piezoelectric materials is considered to have three components: dielectric, elastic, and piezoelectric. The tangent functions with superscript " $"$ " - $\tan \delta^{\prime}, \tan \phi^{\prime}$, and $\tan \theta^{\prime}$-are used to represent "intensive" dielectric, elastic, and piezoelectric loss factors; $\tan \phi_{P}$ represents the "extensive" elastic loss factor and the subscript " $P$ " indicates the PZT [21,28]. In this paper, we use PZT5 for its relatively large losses and low quality factor. Compared with PZT4, which has small losses and a higher quality factor, the usage of PZT5 can illustrate the great impact of PZT losses when they are considered in the equivalent circuit model.

$$
\begin{aligned}
C_{11}^{E *} & =C_{11}^{E}\left(1+j \tan \phi_{P}\right) \\
\varepsilon_{33}^{T *} & =\varepsilon_{33}^{T}\left(1-j \tan \delta^{\prime}\right) \\
s_{11}^{E *} & =s_{11}^{E}\left(1-j \tan \phi^{\prime}\right) \\
d_{31}^{*} & =d_{31}\left(1-j \tan \theta^{\prime}\right)
\end{aligned}
$$

where $C_{11}^{E}$ is the stiffness under a constant electric field, $\varepsilon_{33}^{T}$ is the dielectric constant under constant stress, $s_{11}^{E}$ is the compliance under a constant electric field, and $d_{31}$ is the piezoelectric constant.

A differential equation of motion is the basis for equivalent circuit establishment. Since this structure is a slender beam and we assume that the boundary condition is free-free, with no external force and only axial stress considered, the standard 3D piezoelectric constitutive equation can be reduced to a $1 \mathrm{D}$ form [29]:

$$
\left\{\begin{array}{c}
D_{3}^{*}=\varepsilon_{33}^{T *} E_{3}+d_{31}^{*} X_{1}^{*} \\
S_{1}^{*}=d_{31}^{*} E_{3}+s_{11}^{E *} X_{1}^{*}
\end{array} .\right.
$$

Losses in the piezoelectric patch and metal substrate are included in the derivation, so complex numbers are used and are denoted with a superscript "*”, as mentioned before. Here, $D_{3}$ is the electric 
displacement in the $z$-direction, $E_{3}$ is the electric field in the $z$-direction, $X_{1 \mathrm{i}}$ is the axial stress in the $x$-direction, and $S_{1}$ is the axial strain in the $x$-direction.

Section 0 and PZT in this structure play the main role and act as the excitation source; the motion equation is derived upon it and the corresponding parameters are depicted in Figure 2. Here, $\rho, V$, $m, A$, and $h$ stand for the density, volume, weight, cross-sectional area, and thickness, respectively; the related subscripts " $P$ " and " $M$ " indicate that those parameters describe the PZT and the metal substrate (aluminum), respectively; and similarly hereinafter. A driving voltage $U$ is applied on the electrode surface of the PZT, $U_{0}$ is the amplitude of voltage, and $E_{3}=U / h_{P}$. $L_{w}$ stands for the width of the structure.

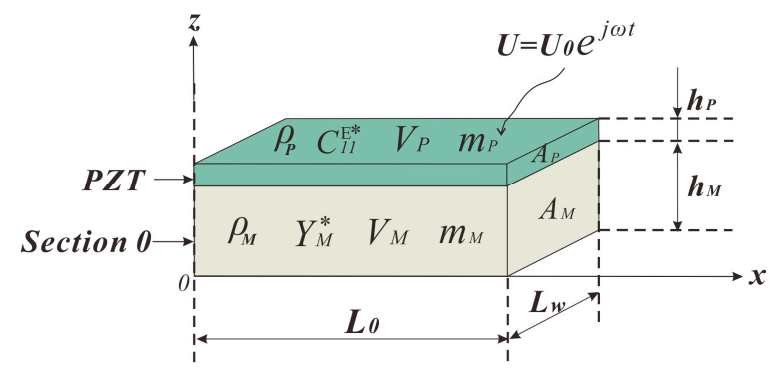

Figure 2. Section 0 and PZT under electric excitation and the corresponding parameters.

Using the Lagrange function and the variational principle [30], the motion equation of the piezoelectric structure under longitudinal vibration mode is obtained:

$$
\rho_{M} A_{M}\left(\frac{\partial^{2} u^{*}}{\partial t^{2}}\right)+\rho_{P} A_{P}\left(\frac{\partial^{2} u^{*}}{\partial t^{2}}\right)=A_{P} C_{11}^{E *}\left(\frac{\partial^{2} u^{*}}{\partial x^{2}}\right)+A_{M} Y_{M}^{*}\left(\frac{\partial^{2} u^{*}}{\partial x^{2}}\right)
$$

where $u^{*}$ is the displacement along the $x$-direction and is a function of both position $x$ and time $t$.

According to the principle of composite materials, we can rewrite Equation (7) as the following:

$$
\rho_{B}\left(\frac{\partial^{2} u^{*}}{\partial t^{2}}\right)=Y_{B}^{*}\left(\frac{\partial^{2} u^{*}}{\partial x^{2}}\right)
$$

where $\rho_{B}$ is the density of the PZT and metal substrate (aluminum) as a composite material and $Y_{B}^{*}$ is the composite Young's modulus as a complex number [31].

$$
\begin{gathered}
\rho_{B}=\frac{m_{M}+m_{P}}{V_{M}+V_{P}} \\
Y_{B}^{*}=\frac{V_{P}}{V_{M}+V_{P}} C_{11}^{E *}+\frac{V_{M}}{V_{M}+V_{P}} Y_{M}^{*}
\end{gathered}
$$

\section{Equivalent Circuit with Four Kinds of Losses}

Equivalent circuits derive from the mathematical statement of the structure, namely, the motion equation. Although the calculation procedures of the equivalent circuit are developed in Mason's edited book [32], the main parameters presented here are in complex numbers. For Section 0 and PZT of this piezoelectric structure, the motion equation is expressed in Equation (8). Since we focus on the longitudinal vibration, a displacement formula for an arbitrary point in Section 0 and PZT is assumed:

$$
u^{*}(x, t)=\left[\alpha \cos \left(k_{0}^{*} x\right)+\beta \sin \left(k_{0}^{*} x\right)\right] e^{j \omega t},
$$


where $\alpha$ and $\beta$ are coefficients that will be introduced later. Here, $k_{0}^{*}$ is the wave number rewritten as a complex number, and

$$
k_{0}^{*}=\omega \sqrt{\frac{\rho_{B}}{Y_{B}^{*}}}
$$

where $\omega$ is the angular frequency.

The velocity formula for an arbitrary point is

$$
\begin{aligned}
v^{*} & =\frac{\partial u^{*}(x, t)}{\partial t} \\
& =j \omega\left[\alpha \cos \left(k_{0}^{*} x\right)+\beta \sin \left(k_{0}^{*} x\right)\right] e^{j \omega t} .
\end{aligned}
$$

The distribution of forces and velocities in Section 0 and PZT is shown in Figure 3, where $v$ stands for velocity and F for force. The subscript " $P$ " represents the PZT, and " $M$ " the metal substrate; the other subscript " 1 " means that the corresponding parameter is located at the position of $x=0$, and "2" means the same but at $x=L_{0}$.

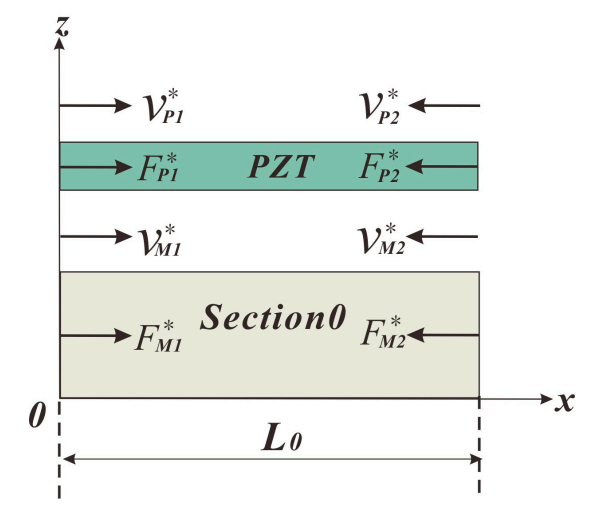

Figure 3. The distribution of forces and velocities in Section 0 and PZT.

\subsection{Equivalent Circuit of PZT}

First of all, we conduct the equivalent circuit of the PZT part. According to Figure 3, we have

$$
\left\{\begin{array}{c}
v_{P 1}^{*}=\left.v_{P 1}^{*}\right|_{x=0} \\
v_{P 2}^{*}=-\left.v_{P 1}^{*}\right|_{x=L_{0}}
\end{array} .\right.
$$

By inserting Equation (13) into (14) and calculating coefficients $\alpha$ and $\beta$, we get

$$
\left\{\begin{array}{c}
\alpha=\frac{v_{P 1}^{*}}{j \omega e^{j \omega t}} \\
\beta=-\frac{1}{j \omega e^{j \omega t}}\left[\frac{v_{P 1}^{*}}{\tan \left(k_{0}^{*} L_{0}\right)}+\frac{v_{P 2}^{*}}{\sin \left(k_{0}^{*} L_{0}\right)}\right] .
\end{array}\right.
$$

The strain of an arbitrary point in the PZT is

$$
\begin{aligned}
S_{1}^{*} & =\frac{\partial u^{*}(x, t)}{\partial x} \\
& =-\frac{v_{P 1}^{*} k_{0}^{*} \sin \left(k_{0}^{*} x\right)}{j \omega}-\frac{k_{0}^{*} \cos \left(k_{0}^{*} x\right)}{j \omega}\left[\frac{v_{P 1}^{*}}{\tan \left(k_{0}^{*} L_{0}\right)}+\frac{v_{P 2}^{*}}{\sin \left(k_{0}^{*} L_{0}\right)}\right] .
\end{aligned}
$$


The corresponding stress is

$$
\begin{aligned}
X_{1 P}^{*} & =\frac{1}{s_{11}^{E *}} S_{1}^{*}-\frac{d_{31}^{*}}{s_{11}^{E *}} E_{3} \\
& =-\frac{v_{P 1}^{*} k_{0}^{*} \sin \left(k_{0}^{*} x\right)}{j \omega s_{11}^{E *}}-\frac{k_{0}^{*} \cos \left(k_{0}^{*} x\right)}{j \omega s_{11}^{E *}}\left[\frac{v_{P 1}^{*}}{\tan \left(k_{0}^{*} L_{0}\right)}+\frac{v_{P 2}^{*}}{\sin \left(k_{0}^{*} L_{0}\right)}\right]-\frac{d_{31}^{*}}{s_{11}^{E *}} E_{3} .
\end{aligned}
$$

Then, the forces can be expressed as

$$
\begin{aligned}
F_{P 1}^{*} & =-\left.A_{P} X_{1 P}^{*}\right|_{x=0} \\
& =\frac{A_{P} k_{0}^{*}}{j \omega s_{11}^{E *}}\left[\frac{v_{P 1}^{*}+v_{P 2}^{*}}{\sin \left(k_{0}^{*} L_{0}\right)}-v_{P 1}^{*} \tan \left(\frac{k_{0}^{*} L_{0}}{2}\right)\right]+\frac{d_{31}^{*}}{s_{11}^{E *} L_{w} U} \\
F_{P 2}^{*} & =-\left.A_{P} X_{1 P}^{*}\right|_{x=L_{0}} \\
& =\frac{A_{P} k_{0}^{*}}{j \omega s_{11}^{E *}}\left[\frac{v_{P 1}^{*}+v_{P 2}^{*}}{\sin \left(k_{0}^{*} L_{0}\right)}-v_{P 2}^{*} \tan \left(\frac{k_{0}^{*} L_{0}}{2}\right)\right]+\frac{d_{31}^{*}}{s_{11}^{E *} L_{w} U .}
\end{aligned}
$$

The following is the calculation of the current flow $I^{*}$. The charge $Q^{*}$ of the electrode surface is

$$
\begin{aligned}
Q^{*} & =\iint D_{3}^{*} d x d y \\
& =\frac{d_{31}^{*}}{s_{11}^{E *}} L_{w}\left[\alpha \cos \left(k_{0}^{*} L_{0}\right)+\beta \sin \left(k_{0}^{*} L_{0}\right)-\alpha\right] e^{j \omega t}+\left(\varepsilon_{33}^{T *}-\frac{d_{31}^{* 2}}{s_{11}^{E *}}\right) L_{w} L_{0} \frac{U_{0} e^{j \omega t}}{h_{P}} .
\end{aligned}
$$

The current flow $I^{*}$ is

$$
\begin{aligned}
I^{*} & =\frac{d Q^{*}}{d t} \\
& =-\frac{d_{31}^{*}}{s_{11}^{E *}} L_{w}\left[v_{P 1}^{*}+v_{P 2}^{*}\right]+j \omega\left(\varepsilon_{33}^{T *}-\frac{d_{31}^{* 2}}{s_{11}^{E *}}\right) L_{w} L_{0} \frac{U_{0} e^{j \omega t}}{h_{P}}
\end{aligned}
$$

and we assume

$$
\begin{gathered}
C_{0}^{*}=\frac{\left(\varepsilon_{33}^{T *}-\frac{d_{31}^{* 2}}{s_{11}^{E *}}\right) L_{w} L_{0}}{h_{P}} \\
N^{*}=\frac{d_{31}^{*} L_{w}}{s_{11}^{E *}} .
\end{gathered}
$$

Meanwhile, we use the following equations to simplify the expression of Equations (18)-(21).

$$
\begin{gathered}
\frac{A_{P} k_{0}^{*}}{j \omega s_{11}^{E *}} \frac{1}{\sin \left(k_{0}^{*} L_{0}\right)}=R_{P 1}+j G_{P 1} \\
\frac{A_{P} k_{0}^{*}}{j \omega s_{11}^{E *}} \tan \left(\frac{k_{0}^{*} L_{0}}{2}\right)=R_{P 2}+j G_{P 2} \\
C_{0}^{*}=C_{01}+j C_{02}
\end{gathered}
$$

In Equations (24) and (25), we collect all the real parts of those parameters together and mark them as $R_{P 1}$ and $R_{P 2}$, which represent resistors (the mechanical energy consumption). The imaginary parts of those parameters are marked as $G_{P 1}$ and $G_{P 2}$, which stand for reactance (the mechanical energy storage). The complete expressions of $R_{P 1}, R_{P 2}, G_{P 1}$, and $G_{P 2}$ are listed in Appendix A. In Equation (26), the real part and imaginary part of $C_{0}^{*}$ are separated into $C_{01}$ and $C_{02}$. 
By inserting Equations (24)-(26) into Equations (18)-(21) correspondingly, we have the final equations to decide the equivalent circuit of PZT, as follows:

$$
\left\{\begin{array}{l}
F_{P 1}^{*}=\left(R_{P 1}+j G_{P 1}\right)\left(v_{P 1}^{*}+v_{P 2}^{*}\right)-\left(R_{P 2}+j G_{P 2}\right) v_{P 1}^{*}+N^{*} U \\
F_{P 2}^{*}=\left(R_{P 1}+j G_{P 1}\right)\left(v_{P 1}^{*}+v_{P 2}^{*}\right)-\left(R_{P 2}+j G_{P 2}\right) v_{P 2}^{*}+N^{*} U \\
I^{*}=-N^{*}\left(v_{P 1}^{*}+v_{P 2}^{*}\right)+j \omega U C_{01}-\omega U C_{02}
\end{array}\right.
$$

Kirchhoff's current law and Kirchhoff's voltage law are applied to build the equivalent circuit of PZT, as shown in Figure 4, where $Z_{0}=\frac{1}{j \omega C_{01}}, Z_{1}=\frac{1}{-\omega C_{02}}$.

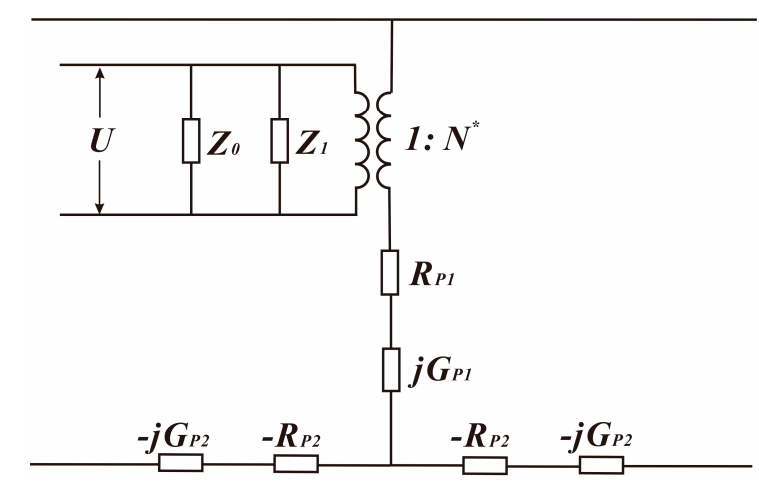

Figure 4. The equivalent circuit of the PZT.

\subsection{Equivalent Circuit of Section 0 and Complete Equivalent Circuit}

According to Figure 3, and ignoring the effect of the bonding layer, we have

$$
\left\{\begin{array}{l}
v_{M 1}^{*}=v_{P 1}^{*} \\
v_{M 2}^{*}=v_{P 2}^{*}
\end{array}\right.
$$

The strain of an arbitrary point in Section 0 is

$$
\begin{aligned}
S_{1}^{*} & =\frac{\partial u^{*}(x, t)}{\partial x} \\
& =-\frac{v_{M 1}^{*} k_{0}^{*} \sin \left(k_{0}^{*} x\right)}{j \omega}-\frac{k_{0}^{*} \cos \left(k_{0}^{*} x\right)}{j \omega}\left[\frac{v_{M 1}^{*}}{\tan \left(k_{0}^{*} L_{0}\right)}+\frac{v_{M 2}^{*}}{\sin \left(k_{0}^{*} L_{0}\right)}\right] .
\end{aligned}
$$

The corresponding stress is

$$
\begin{aligned}
X_{1 M}^{*} & =Y_{B}^{*} S_{1}^{*} \\
& =-\frac{Y_{B}^{*} v_{M 1}^{*} k_{0}^{*} \sin \left(k_{0}^{*} x\right)}{j \omega}-\frac{Y_{B}^{*} k_{0}^{*} \cos \left(k_{0}^{*} x\right)}{j \omega}\left[\frac{v_{M 1}^{*}}{\tan \left(k_{0}^{*} L_{0}\right)}+\frac{v_{M 2}^{*}}{\sin \left(k_{0}^{*} L_{0}\right)}\right] .
\end{aligned}
$$

The forces can then be expressed as

$$
\begin{aligned}
F_{M 1}^{*} & =-\left.A_{M} X_{1 M}^{*}\right|_{x=0} \\
& =\frac{A_{M} Y_{B}^{*} k_{0}^{*}}{j \omega}\left[\frac{v_{M 1}^{*}+v_{M 2}^{*}}{\sin \left(k_{0}^{*} L_{0}\right)}-v_{M 1}^{*} \tan \left(\frac{k_{0}^{*} L_{0}}{2}\right)\right] \\
F_{M 2}^{*} & =-\left.A_{M} X_{1 M}^{*}\right|_{x=L_{0}} \\
& =\frac{A_{M} Y_{B}^{*} k_{0}^{*}}{j \omega}\left[\frac{v_{M 1}^{*}+v_{M 2}^{*}}{\sin \left(k_{0}^{*} L_{0}\right)}-v_{M 2}^{*} \tan \left(\frac{k_{0}^{*} L_{0}}{2}\right)\right] .
\end{aligned}
$$


We use the following equations to simplify the expression of Equations (31) and (32). The complete expressions of $R_{M 1}, R_{M 2}, G_{M 1}$, and $G_{M 2}$ are listed in Appendix A and their meanings are the same as introduced before.

$$
\begin{aligned}
& \frac{A_{M} Y_{B}^{*} k_{0}^{*}}{j \omega} \frac{1}{\sin \left(k_{0}^{*} L_{0}\right)}=R_{M 1}+j G_{M 1} \\
& \frac{A_{M} Y_{B}^{*} k_{0}^{*}}{j \omega} \tan \left(\frac{k_{0}^{*} L_{0}}{2}\right)=R_{M 2}+j G_{M 2}
\end{aligned}
$$

By inserting Equations (33) and (34) into Equations (31) and (32) correspondingly, we have the final equations to decide the equivalent circuit of Section 0 , as follows:

$$
\left\{\begin{array}{l}
F_{M 1}^{*}=\left(R_{M 1}+j G_{M 1}\right)\left(v_{M 1}^{*}+v_{M 2}^{*}\right)-\left(R_{M 2}+j G_{M 2}\right) v_{M 1}^{*} \\
F_{M 2}^{*}=\left(R_{M 1}+j G_{M 1}\right)\left(v_{M 1}^{*}+v_{M 2}^{*}\right)-\left(R_{M 2}+j G_{M 2}\right) v_{M 2}^{*}
\end{array} .\right.
$$

Then, Kirchhoff's current law and voltage law are applied to build the equivalent circuit of Section 0, as shown in Figure 5.

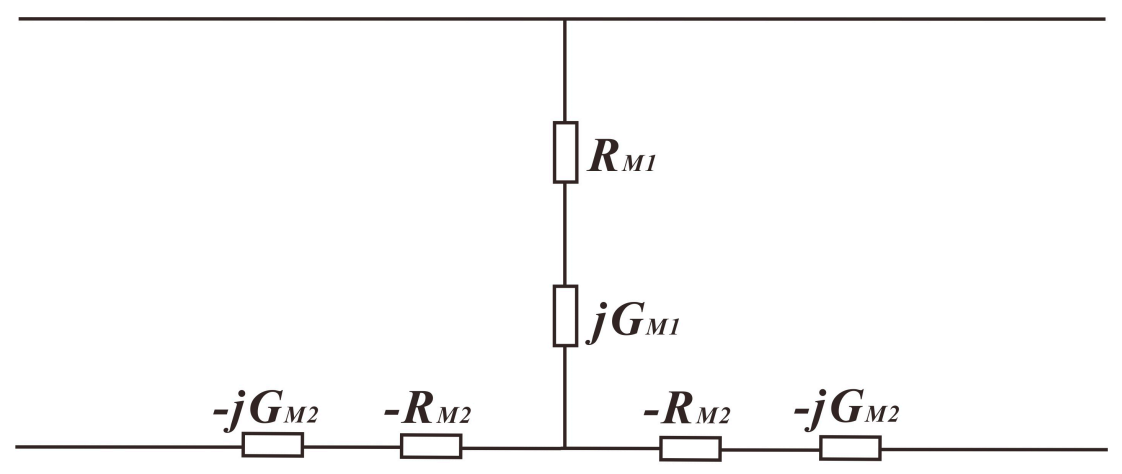

Figure 5. The equivalent circuit of Section 0.

The equivalent circuits of remaining sections have the same derivation procedures as that of Section 0, apart from the different lengths and different directions of forces and velocities, as shown in Figure 6.

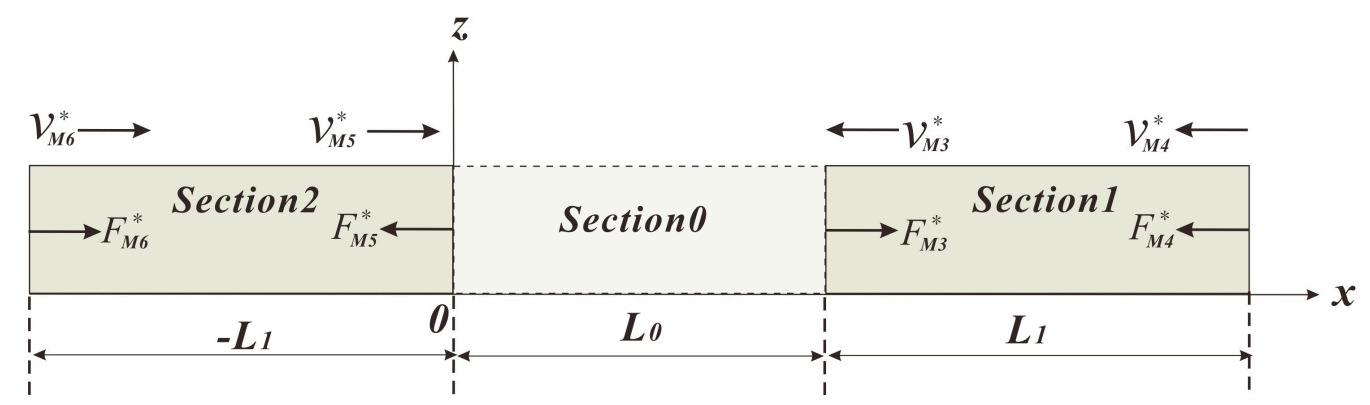

Figure 6. Schematic diagram of Section 1 and Section 2.

Finally, by combining the above separate equivalent circuits together, we can acquire the complete equivalent circuit of the introduced piezoelectric structure, as shown in Figure 7. The complete expressions of $R_{M 3}, R_{M 4}, G_{M 3}$, and $G_{M 4}$ are listed in Appendix A. This equivalent circuit represents the longitudinal vibration mode of a beam with a PZT covering part of the beam length. The principle of our new equivalent circuit differs from the conventional Mason's equivalent circuit, for losses in the metal substrate and PZT are integrated, as mentioned in the introduction. The effectiveness of the proposed equivalent circuit will be verified through experiments. 


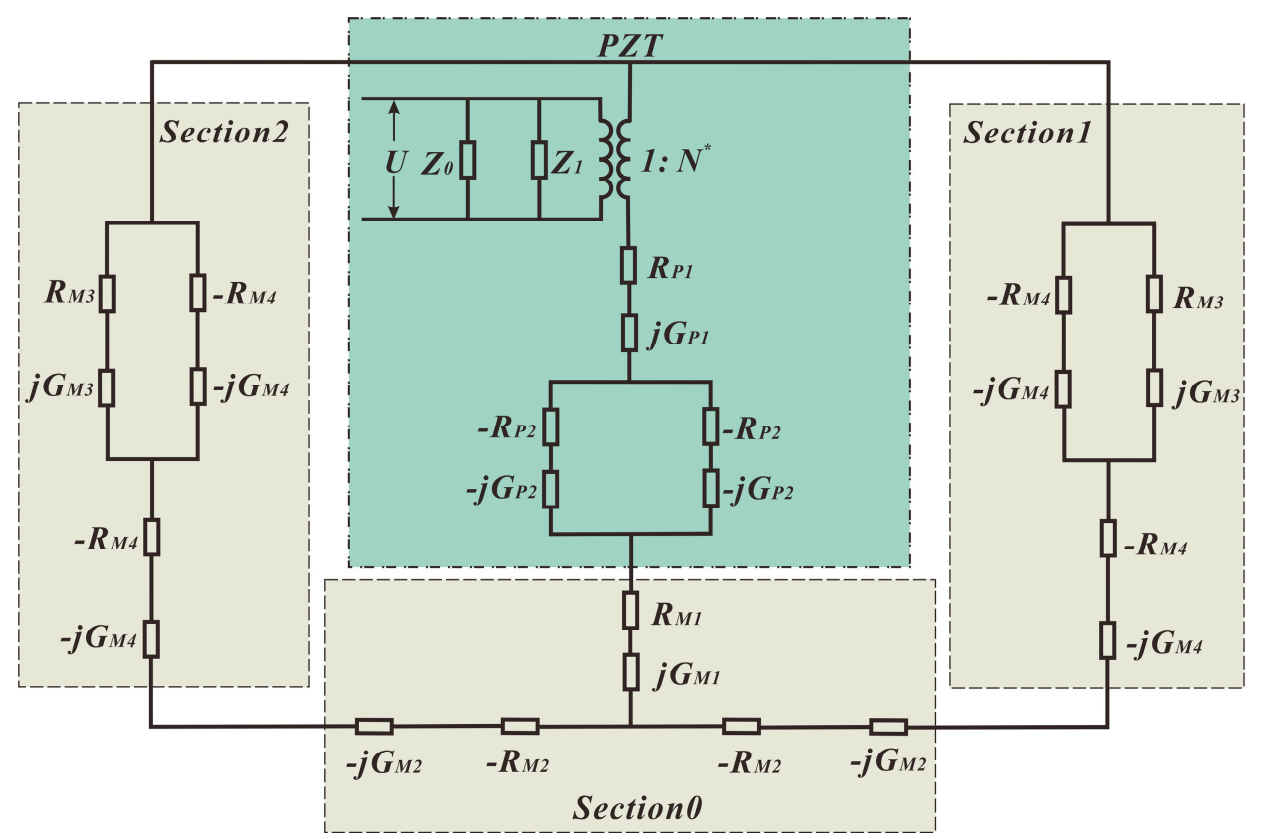

Figure 7. Complete equivalent circuit of the piezoelectric structure.

\section{Experiment}

In order to verify the effectiveness of our equivalent circuit, a prototype of this piezoelectric structure was fabricated and tested using a Polytec PSV-400 laser vibrometer (PolyTec Inc., Waldbronn, Germany). The experimental setup is shown in Figure 8. The piezoelectric structure is supposed to work at free-free boundary conditions, so it was lightly fixed using expanded polystyrene boards to avoid restriction on its longitudinal vibration. The driving signal was generated by a function generator (33210A, Keysight Technologies, Inc., Santa Rosa, CA, USA) and amplified by a power amplifier (HFVA-42, Nanjing Foneng Technology Industry Co., Ltd., Nanjing, China). The vibrometer measurement system contained a Junction Box, Vibrometer Controller, Data Management System, Scanning Head, computer, and monitor, as shown in Figure 8.

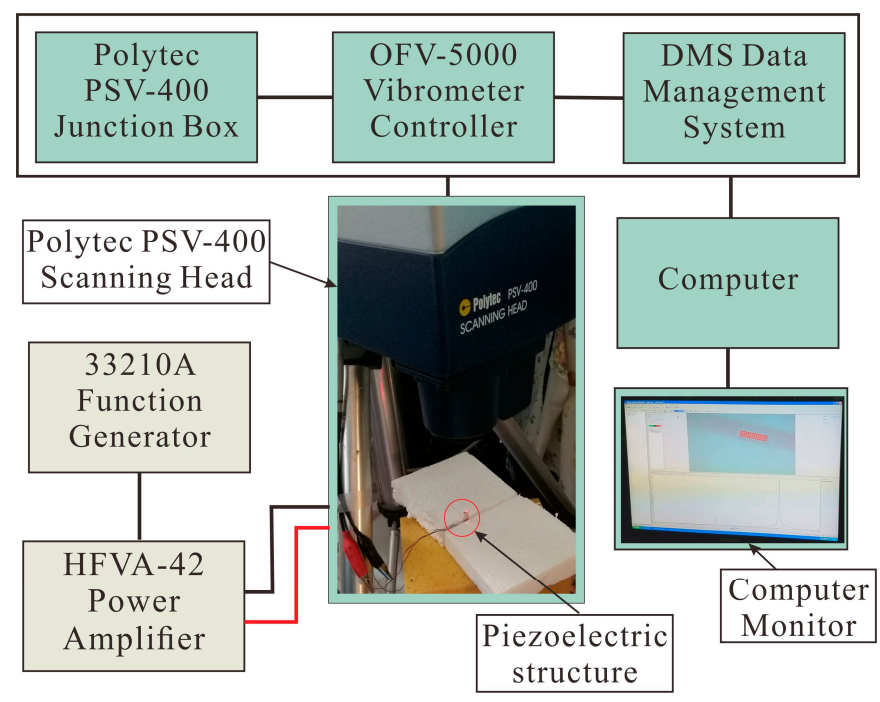

Figure 8. Experimental setup of vibrometer measurement. 
Figure 9 shows the vibrometer measurement results of this structure. The tested edge surface is perpendicular to the $x$-axis (Figure 1) and demonstrates longitudinal vibration at a frequency of $81.4 \mathrm{kHz}$. $A_{o r}$ stands for the original cross-sectional area, while $A_{c}$ and $A_{e}$ are the contraction and extension of the original cross-sectional area, respectively. This structure was also measured using an Agilent 4294A impedance analyzer (Keysight Technologies, Inc., Santa Rosa, CA, USA); the frequency tested by the impedance analyzer was $81.5 \mathrm{kHz}$, which is close to the vibrometer result of $81.4 \mathrm{kHz}$. An impedance curve was obtained and compared with the equivalent circuit result. The geometry and material parameters, including loss factors, are listed in Tables 1 and 2. For the loss factor of aluminum $\tan \phi_{M}$, since the loss factor decreased with increasing frequency [33] and this structure was tested at high frequency (above $20 \mathrm{kHz}$ ), we assumed that it was equal to $1.0 \times 10^{-3}[34,35]$. The piezoelectric ceramic we used was Haiying P-51 (Haiying Enterprise Group Co., Ltd., Wuxi, Jiangsu, China), a PZT5 ceramic. Compared with PZT4, the loss factors in $\tan \phi^{\prime}, \tan \theta^{\prime}$, and $\tan \phi_{P}$ of the P-51 are much higher; thus, the impact of losses can be clearly seen in the impedance curves in Figure 10.

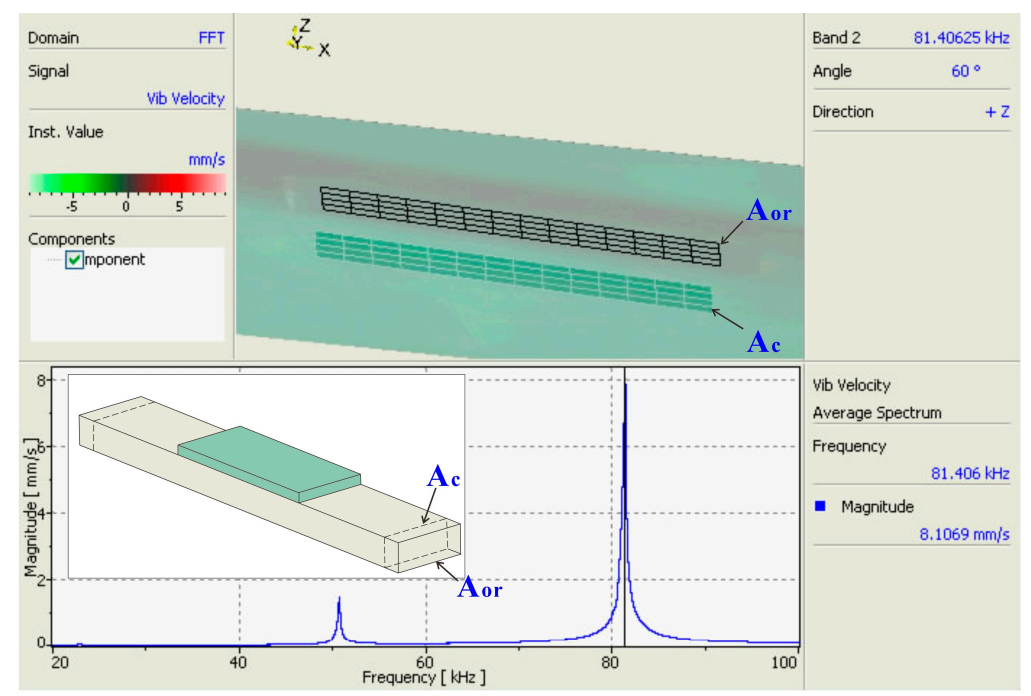

(a)

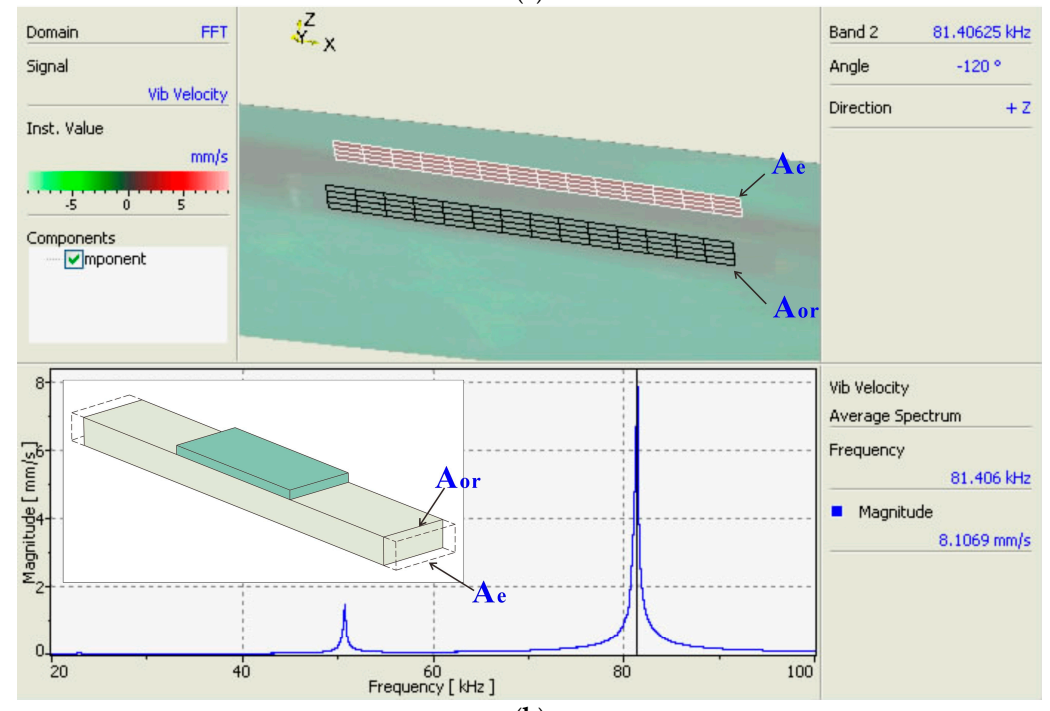

(b)

Figure 9. Laser vibrometer result of piezoelectric structure under longitudinal vibration mode: (a) longitudinal vibration under contraction situation; (b) longitudinal vibration under extension situation. 


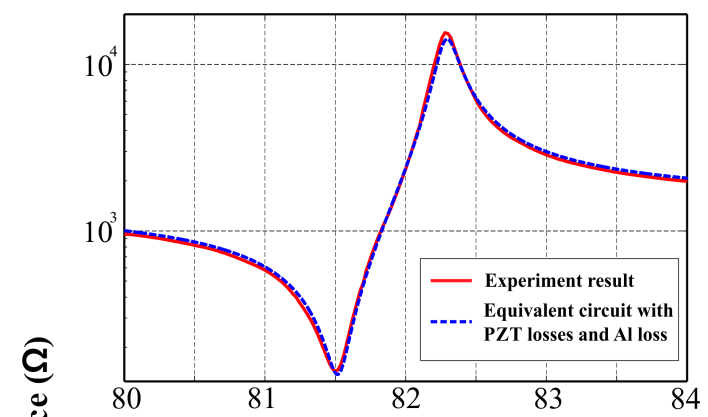

( a )

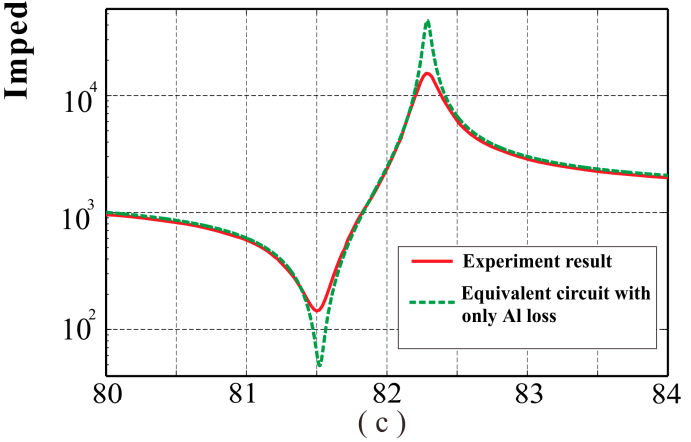

Frequency $(\mathbf{k H z})$

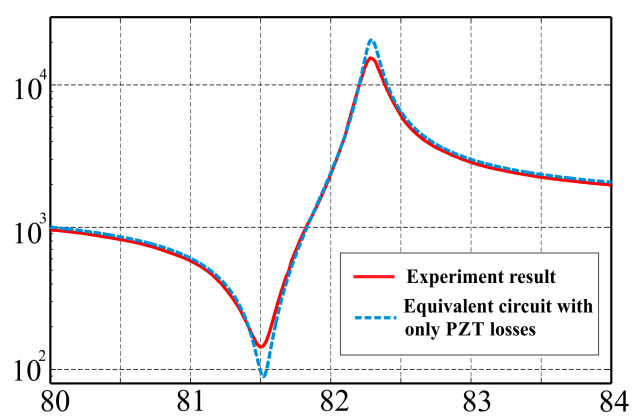

(b)

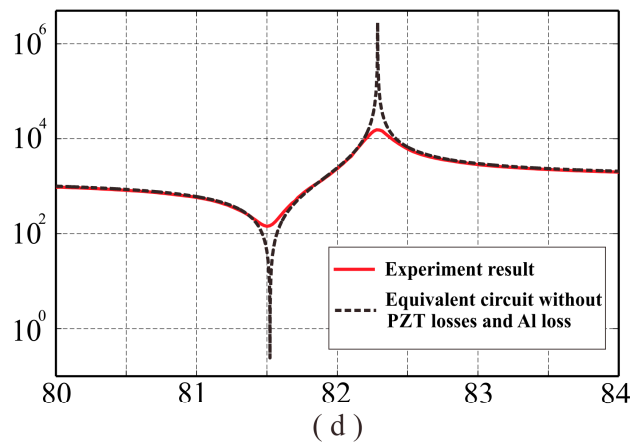

Figure 10. Comparison of impedance curves between experiment and equivalent circuit simulations: (a) experiment vs equivalent circuit with three PZT losses and aluminum loss (Al loss); (b) experiment vs equivalent circuit with three PZT losses; (c) experiment vs equivalent circuit with Al loss; (d) experiment vs equivalent circuit with no losses.

Table 1. Loss factors of aluminum and PZT5.

\begin{tabular}{cccccc}
\hline Parameter & $\tan \phi_{M}$ & $\tan \phi_{P}$ & $\tan \delta^{\prime}$ & $\tan \phi^{\prime}$ & $\tan \boldsymbol{\theta}^{\prime}$ \\
\hline Value & $1.000 \times 10^{-3}$ & $10.20 \times 10^{-3}$ & $2.000 \times 10^{-2}$ & $11.70 \times 10^{-3}$ & $21.80 \times 10^{-3}$ \\
\hline
\end{tabular}

Table 2. Geometry and material parameters of the piezoelectric structure.

\begin{tabular}{cccccc}
\hline Parameter & Value & Parameter & Value & Parameter & Value \\
\hline$L_{0}(\mathrm{~mm})$ & 12.60 & $h_{P}(\mathrm{~mm})$ & 0.7000 & $S_{11}^{E}\left(\mathrm{~m}^{2} / \mathrm{N}\right)$ & $15.00 \times 10^{-12}$ \\
$L_{1}(\mathrm{~mm})$ & 10.40 & $\rho_{M}\left(\mathrm{~kg} / \mathrm{m}^{3}\right)$ & 2700 & $d_{31}(\mathrm{C} / \mathrm{N})$ & $-185.0 \times 10^{-12}$ \\
$L_{w}(\mathrm{~mm})$ & 5.300 & $\rho_{P}\left(\mathrm{~kg} / \mathrm{m}^{3}\right)$ & 7450 & $\varepsilon_{33}^{T}$ & 1750 \\
$h_{M}(\mathrm{~mm})$ & 2.100 & $Y_{M}(\mathrm{Gpa})$ & 69.00 & $C_{11}^{E}\left(\mathrm{~N} / \mathrm{m}^{2}\right)$ & $15.00 \times 10^{10}$ \\
\hline
\end{tabular}

Figure 10a demonstrates that the impedance-frequency result of the equivalent circuit considering both the three PZT losses and the elastic loss of the metal substrate (aluminum loss or Al loss) has good agreement with the experimental result. It is notable that the deviations in Figure 10 are mostly the values of impedances $Z_{\mathrm{fR}}$ and $Z_{\mathrm{fA}}$ in resonance and antiresonance frequencies, respectively, while the frequency values simulated by the equivalent circuit have high accuracy and discrepancies in resonance and antiresonance frequencies are close to $0 \%$. As for the values of impedances, for neglect of the aluminum loss (Figure 10b) or for neglect of the PZT losses (Figure 10c), the discrepancies in impedance values become higher compared with the experiment results. Moreover, the neglect of both the PZT losses and the aluminum loss leads to extremely high discrepancies (Figure 10d). The details are listed in Table 3. In summary, the consideration of losses (both PZT losses and Al loss) in the equivalent circuit increases its accuracy and thus makes it more effective in the study of piezoelectric structures. 
Table 3. Comparison of results between experiment and equivalent circuit (EC) simulations.

\begin{tabular}{lcccc}
\hline & $\mathbf{f}_{\mathbf{R}}(\mathbf{H z})$ & $\mathbf{f}_{\mathbf{A}} \mathbf{( H z )}$ & $\mathbf{Z}_{\mathbf{f R}}(\boldsymbol{\Omega})$ & $\mathbf{Z}_{\mathbf{f A}}(\boldsymbol{\Omega})$ \\
\hline Experiment & 81,500 & 82,280 & 143.78 & 15,479 \\
EC with PZT losses and Al loss & 81,516 & 82,295 & 137.50 & 14,169 \\
Percentage of error (\%) & 0.019632 & 0.018230 & 4.3678 & 8.4631 \\
EC with only PZT losses & 81,520 & 82,291 & 89.301 & 20,765 \\
Percentage of error (\%) & 0.024540 & 0.013369 & 37.890 & 34.149 \\
EC with only Al loss & 81,521 & 82,287 & 49.116 & 43,724 \\
Percentage of error (\%) & 0.025767 & 0.0085075 & 65.839 & 182.47 \\
EC without PZT losses and Al loss & 81,522 & 82,287 & 0.24246 & $2,817,880$ \\
Percentage of error $(\%)$ & 0.026994 & 0.0085075 & 99.831 & 18,105 \\
\hline
\end{tabular}

\section{Conclusions}

This paper describes an equivalent circuit of a piezoelectric structure which consists of a slender aluminum beam and a PZT patch. The longitudinal vibration mode of this structure was studied, and the elastic loss of aluminum and three PZT losses were built into the equivalent circuit. The result of the equivalent circuit, namely, the impedance curve of this structure, has good agreement with the experiment result. The typical frequencies such as resonance and antiresonance simulated by the equivalent circuit are almost the same as the experiment results, while the values of impedances in resonance and antiresonance have percent errors of $4.3678 \%$ and $8.4631 \%$, respectively. By contrast, neglect of the elastic loss of aluminum in the equivalent circuit leads to discrepancies of $37.890 \%$ and $34.149 \%$ in values of impedances, neglect of the PZT losses leads to discrepancies of $65.839 \%$ and $182.47 \%$, and neglect of both the PZT losses and the aluminum loss leads to discrepancies of $99.831 \%$ and $18,105 \%$. The introduction of PZT losses and aluminum loss to the equivalent circuit dramatically contributed to the result accuracy. This result can be extended to the analysis and design of piezoelectric sensors and actuators. In this paper, only longitudinal vibration is investigated; however, in practical applications, such as in multimode ultrasonic motors, bending or torsional modes are involved. Thus, the next step of this work is to study the equivalent circuits combined with multiple vibration modes on more practical assumptions, and to increase the result accuracy of equivalent circuits containing losses.

Acknowledgments: This work is supported by the National Natural Science Foundation of China (Grant No.51577112).

Author Contributions: Tao Yuan proposed the method and performed the theoretical analysis; Chaodong Li prepared the prototypes and experiment setup; Pingqing Fan and Tao Yuan performed the experiments; Tao Yuan wrote the paper.

Conflicts of Interest: The authors declare no conflict of interest.

\section{Appendix A}

The real part $R_{P 1}$ and imaginary part $G_{P 1}$ in the equivalent circuit of the PZT are

$$
\begin{aligned}
& R_{P 1}=\frac{A_{P}\left(K_{O A} \chi_{1}+K_{O B} \chi_{2}\right)}{\omega S_{11}^{E}\left(\chi_{1}^{2}+\chi_{2}^{2}\right)} \\
& G_{P 1}=\frac{A_{P}\left(K_{O B} \chi_{1}-K_{O A} \chi_{2}\right)}{\omega S_{11}^{E}\left(\chi_{1}^{2}+\chi_{2}^{2}\right)}
\end{aligned}
$$

where $\omega$ is the angular frequency, $\omega=2 \pi f$, and $f$ is frequency.

$$
\begin{gathered}
\delta_{1}=\frac{V_{P} C_{11}^{E}}{V_{P}+V_{M}}+\frac{V_{M} Y_{M}}{V_{P}+V_{M}} \\
\delta_{2}=\frac{V_{P} C_{11}^{E} \tan \phi_{P}}{V_{P}+V_{M}}+\frac{V_{M} Y_{M} \tan \phi_{M}}{V_{P}+V_{M}}
\end{gathered}
$$




$$
\begin{array}{r}
K_{O A}=\sqrt{\frac{\omega^{2} \rho_{B}\left(\sqrt{\delta_{1}^{2}+\delta_{2}^{2}}+\delta_{1}\right)}{2\left(\delta_{1}^{2}+\delta_{2}^{2}\right)}} \\
K_{O B}=\sqrt{\frac{\omega^{2} \rho_{B}\left(\sqrt{\delta_{1}^{2}+\delta_{2}^{2}}-\delta_{1}\right)}{2\left(\delta_{1}^{2}+\delta_{2}^{2}\right)}} \\
\chi_{1}=\tan \phi^{\prime} \sin \left(K_{O A} L_{0}\right) \cosh \left(K_{O B} L_{0}\right)-\cos \left(K_{O A} L_{0}\right) \sinh \left(K_{O B} L_{0}\right) \\
\chi_{2}=\tan \phi^{\prime} \cos \left(K_{O A} L_{0}\right) \sinh \left(K_{O B} L_{0}\right)+\sin \left(K_{O A} L_{0}\right) \cosh \left(K_{O B} L_{0}\right)
\end{array}
$$

The real part $R_{P 2}$ and imaginary part $G_{P 2}$ in the equivalent circuit of PZT are

$$
\begin{aligned}
& R_{P 2}=\frac{A_{P}\left(\chi_{3} \chi_{5}+\chi_{4} \chi_{6}\right)}{\omega S_{11}^{E}\left(\chi_{5}^{2}+\chi_{6}^{2}\right)} \\
& G_{P 2}=\frac{A_{P}\left(\chi_{4} \chi_{5}-\chi_{3} \chi_{6}\right)}{\omega S_{11}^{E}\left(\chi_{5}^{2}+\chi_{6}^{2}\right)}
\end{aligned}
$$

where

$$
\begin{gathered}
\chi_{3}=K_{O A} \tan \left(\frac{K_{O A} L_{0}}{2}\right)-K_{O B} \tanh \left(\frac{K_{O B} L_{0}}{2}\right) \\
\chi_{4}=K_{O A} \tanh \left(\frac{K_{O B} L_{0}}{2}\right)+K_{O B} \tan \left(\frac{K_{O A} L_{0}}{2}\right) \\
\chi_{5}=\tan \left(\frac{K_{O A} L_{0}}{2}\right) \tanh \left(\frac{K_{O B} L_{0}}{2}\right)+\tan \phi^{\prime} \\
\chi_{6}=1-\tan \phi^{\prime} \tan \left(\frac{K_{O A} L_{0}}{2}\right) \tanh \left(\frac{K_{O B} L_{0}}{2}\right)
\end{gathered}
$$

and

$$
\begin{gathered}
C_{01}=\frac{L_{0} L_{w}}{h_{P}}\left[\varepsilon_{33}^{T}-\frac{d_{31}^{2}\left(1-\tan {\theta^{\prime}}^{2}+2 \tan \theta^{\prime} \tan \phi^{\prime}\right)}{S_{11}^{E}\left(1+\tan \phi^{\prime 2}\right)}\right] \\
C_{02}=\frac{L_{0} L_{w}}{h_{P}}\left[-\frac{d_{31}^{2}\left(\tan \phi^{\prime}-\tan \phi^{\prime} \tan {\theta^{\prime 2}}^{2}-2 \tan \theta^{\prime}\right)}{S_{11}^{E}\left(1+\tan \phi^{\prime 2}\right)}-\varepsilon_{33}^{T} \tan \delta^{\prime}\right] .
\end{gathered}
$$

The real part $R_{M 1}$ and imaginary part $G_{M 1}$ in the equivalent circuit of the metal substrate (Section 0) are

$$
\begin{aligned}
& R_{M 1}=\frac{A_{M}\left(\chi_{7} \chi_{9}+\chi_{8} \chi_{10}\right)}{\omega\left(\chi_{9}^{2}+\chi_{10}^{2}\right)} \\
& G_{M 1}=\frac{A_{M}\left(\chi_{8} \chi_{9}-\chi_{7} \chi_{10}\right)}{\omega\left(\chi_{9}^{2}+\chi_{10}^{2}\right)}
\end{aligned}
$$

where

$$
\begin{gathered}
\chi_{7}=\delta_{1} K_{O A}-\delta_{2} K_{O B} \\
\chi_{8}=\delta_{1} K_{O B}+\delta_{2} K_{O A} \\
\chi_{9}=-\cos \left(K_{O A} L_{0}\right) \sinh \left(K_{O B} L_{0}\right) \\
\chi_{10}=\sin \left(K_{O A} L_{0}\right) \cosh \left(K_{O B} L_{0}\right) .
\end{gathered}
$$


The real part $R_{M 2}$ and imaginary part $G_{M 2}$ in the equivalent circuit of the metal substrate (Section 0) are

$$
\begin{aligned}
& R_{M 2}=\frac{A_{M}\left(\chi_{11} \chi_{13}+\chi_{12}\right)}{\omega\left(\chi_{13}^{2}+1\right)} \\
& G_{M 2}=\frac{A_{M}\left(\chi_{12} \chi_{13}-\chi_{11}\right)}{\omega\left(\chi_{13}^{2}+1\right)}
\end{aligned}
$$

where

$$
\begin{gathered}
\chi_{11}=\left(\delta_{1} K_{O A}-\delta_{2} K_{O B}\right) \tan \left(\frac{K_{O A} L_{0}}{2}\right)-\left(\delta_{1} K_{O B}+\delta_{2} K_{O A}\right) \tanh \left(\frac{K_{O B} L_{0}}{2}\right) \\
\chi_{12}=\left(\delta_{1} K_{O A}-\delta_{2} K_{O B}\right) \tanh \left(\frac{K_{O B} L_{0}}{2}\right)+\left(\delta_{1} K_{O B}+\delta_{2} K_{O A}\right) \tan \left(\frac{K_{O A} L_{0}}{2}\right) \\
\chi_{13}=\tan \left(\frac{K_{O A} L_{0}}{2}\right) \tanh \left(\frac{K_{O B} L_{0}}{2}\right) .
\end{gathered}
$$

The real part $R_{M 3}$ and imaginary part $G_{M 3}$ in the equivalent circuit of the metal substrate (Sections 1 and 2) are

$$
\begin{aligned}
R_{M 3} & =\frac{A_{M} Y_{M}\left(\chi_{14} \chi_{16}+\chi_{15} \chi_{17}\right)}{\omega\left(\chi_{16}^{2}+\chi_{17}^{2}\right)} \\
G_{M 3} & =\frac{A_{M} Y_{M}\left(\chi_{15} \chi_{16}-\chi_{14} \chi_{17}\right)}{\omega\left(\chi_{16}^{2}+\chi_{17}^{2}\right)}
\end{aligned}
$$

where

$$
\begin{gathered}
\chi_{14}=K_{O A}-K_{O B} \tan \phi_{E} \\
\chi_{15}=K_{O B}+K_{O A} \tan \phi_{E} \\
\chi_{16}=-\cos \left(K_{O A} L_{1}\right) \sinh \left(K_{O B} L_{1}\right) \\
\chi_{17}=\sin \left(K_{O A} L_{1}\right) \cosh \left(K_{O B} L_{1}\right) .
\end{gathered}
$$

The real part $R_{M 4}$ and imaginary part $G_{M 4}$ in the equivalent circuit of the metal substrate (Sections 1 and 2) are

$$
\begin{aligned}
R_{M 4} & =\frac{A_{M} Y_{M}\left(\chi_{18} \chi_{20}+\chi_{19}\right)}{\omega\left(\chi_{20}^{2}+1\right)} \\
G_{M 4} & =\frac{A_{M} Y_{M}\left(\chi_{19} \chi_{20}-\chi_{18}\right)}{\omega\left(\chi_{20}^{2}+1\right)}
\end{aligned}
$$

where

$$
\begin{gathered}
\chi_{18}=\left(K_{O A}-K_{O B} \tan \phi_{E}\right) \tan \left(\frac{K_{O A} L_{1}}{2}\right)-\left(K_{O B}+K_{O A} \tan \phi_{E}\right) \tanh \left(\frac{K_{O B} L_{1}}{2}\right) \\
\chi_{19}=\left(K_{O A}-K_{O B} \tan \phi_{E}\right) \tanh \left(\frac{K_{O B} L_{1}}{2}\right)+\left(K_{O B}+K_{O A} \tan \phi_{E}\right) \tan \left(\frac{K_{O A} L_{1}}{2}\right) \\
\chi_{20}=\tan \left(\frac{K_{O A} L_{1}}{2}\right) \tanh \left(\frac{K_{O B} L_{1}}{2}\right) .
\end{gathered}
$$




\section{Appendix B}

Table A1. Nomenclature.

\begin{tabular}{|c|c|}
\hline Symbol & Meaning \\
\hline$A_{c}$ & cross-sectional area of metal substrate in contraction situation \\
\hline$A_{e}$ & cross-sectional area of metal substrate in extension situation \\
\hline$\alpha$ & coefficient in displacement formula \\
\hline$A_{M}$ & cross-sectional area of metal substrate \\
\hline$A_{o r}$ & cross-sectional area of metal substrate in original position \\
\hline$A_{P}$ & cross-sectional area of PZT \\
\hline$\beta$ & coefficient in displacement formula \\
\hline$C_{0}^{*}$ & capacitor as a complex number \\
\hline$C_{01}$ & real part of $C_{0}^{*}$ \\
\hline$C_{02}$ & imaginary part of $C_{0}^{*}$ \\
\hline$C_{11}^{E}$ & stiffness under constant electric field \\
\hline$C_{11}^{E *}$ & stiffness under constant electric field as a complex number \\
\hline$d_{31}$ & piezoelectric constant \\
\hline$d_{31}^{*}$ & piezoelectric constant as a complex number \\
\hline$D_{3}^{*}$ & electric displacement of $z$-direction as a complex number \\
\hline$\delta_{i}(i=1,2)$ & coefficients in the formula of equivalent circuit \\
\hline$e_{31}^{*}$ & piezoelectric constant as a complex number \\
\hline$\varepsilon_{33}^{T, 1}$ & dielectric constant under constant stress \\
\hline$\varepsilon_{33}^{T *}$ & dielectric constant under constant stress as a complex number \\
\hline$E_{3}$ & electric field in $z$-direction \\
\hline$f_{A}$ & antiresonance frequency \\
\hline$f_{R}$ & resonance frequency \\
\hline$F_{M i}^{*}(i=1, \ldots, 6)$ & forces of metal substrate as a complex number \\
\hline$F_{P i}^{*}(i=1,2)$ & forces of PZT as a complex number \\
\hline$G_{M i}(i=1, \ldots, 4)$ & $\begin{array}{l}\text { imaginary parts of complex numbers in equivalent circuit of metal } \\
\text { substrate }\end{array}$ \\
\hline$G_{P i}(i=1,2)$ & imaginary parts of complex numbers in equivalent circuit of PZT \\
\hline$h_{M}$ & thickness of metal substrate \\
\hline$h_{P}$ & thickness of PZT \\
\hline$I^{*}$ & current as a complex number \\
\hline$j$ & imaginary notation \\
\hline$k_{0}^{*}$ & wave number as a complex number \\
\hline$K_{O A}$ & coefficients in the formula of equivalent circuit \\
\hline$K_{O B}$ & coefficients in the formula of equivalent circuit \\
\hline$L_{0}$ & length of Section 0 \\
\hline$L_{1}$ & length of Section 1 and Section 2 \\
\hline$L_{w}$ & width of piezoelectric structure \\
\hline$m_{M}$ & weight of metal substrate in Section 0 \\
\hline$m_{P}$ & weight of PZT in Section 0 \\
\hline$N^{*}$ & force factor as a complex number \\
\hline$v^{*}$ & velocity as a complex number \\
\hline$v_{M i}^{*}(i=1, \ldots, 6)$ & velocity of metal substrate as a complex number \\
\hline$v_{P i}^{*}(i=1,2)$ & velocity of PZT as a complex number \\
\hline$\omega$ & angular frequency \\
\hline$\chi_{i}(i=1, \ldots, 20)$ & coefficients in the formula of equivalent circuit \\
\hline$Q^{*}$ & charge of PZT electrode surface \\
\hline$\tilde{\rho}_{B}$ & density of composite structure \\
\hline$\rho_{M}$ & density of metal substrate \\
\hline$\rho_{P}$ & density of PZT \\
\hline$R_{M i}(i=1, \ldots, 4)$ & real parts of complex numbers in equivalent circuit of metal \\
\hline$R_{P i}(i=1,2)$ & $\begin{array}{l}\text { substrate } \\
\text { real parts of complex numbers in equivalent circuit of PZT }\end{array}$ \\
\hline$S_{1}^{*}$ & strain as a complex number \\
\hline$S_{11}^{E}$ & compliance under constant electric field \\
\hline$S_{11}^{E *}$ & compliance under constant electric field as a complex number \\
\hline$t$ & time \\
\hline
\end{tabular}


Table A1. Cont.

\begin{tabular}{cc}
\hline Symbol & Meaning \\
\hline $\tan \delta^{\prime}$ & "intensive" dielectric loss factor of PZT \\
$\tan \phi^{\prime}$ & "intensive" elastic loss factor of PZT \\
$\tan \phi_{M}$ & elastic loss factor of metal substrate \\
$\tan p h_{P}$ & "extensive" elastic loss factor of PZT \\
$\tan \theta^{\prime}$ & "intensive" piezoelectric loss factor of PZT \\
$u^{*}$ & displacement along the $x$-direction \\
$U$ & driving voltage \\
$U_{0}$ & amplitude of driving voltage \\
$V_{M}$ & volume of metal substrate in Section 0 \\
$V_{P}$ & volume of PZT \\
$X_{1}^{*}$ & stress as a complex number \\
$X_{1 M}^{*}$ & stress of PZT as a complex number \\
$X_{1 P}^{*}$ & stress of metal substrate as complex number \\
$Y_{B}^{*}$ & stres nounger \\
$Y_{M}^{*}$ & composite Young's modulus as a complex number \\
$Y_{M}^{*}$ & Young's modus of metal substrate \\
$Z_{0}$ & Young's modulus of metal substrate as a complex number \\
$Z_{1}$ & the expression of $C_{01}$ in equivalent circuit \\
$Z_{f A}$ & the expression of $C_{02}$ in equivalent circuit \\
$Z_{f R}$ & impedance in antiresonance frequency \\
& impedance in resonance frequency \\
\hline
\end{tabular}

\section{References}

1. Zhu, C.; Chu, X.; Yuan, S.; Zhong, Z.; Zhao, Y.; Gao, S. Development of an ultrasonic linear motor with ultra-positioning capability and four driving feet. Ultrasonics 2016, 72, 66-72. [CrossRef] [PubMed]

2. El-Sayed, A.M.; Abo-Ismail, A.; El-Melegy, M.T.; Hamzaid, N.A.; Osman, N.A.A. Development of a Micro-Gripper Using Piezoelectric Bimorphs. Sensors 2013, 13, 5826-5840. [CrossRef] [PubMed]

3. Faegh, S.; Jalili, N.; Sridhar, S. A self-sensing piezoelectric microcantilever biosensor for detection of ultrasmall adsorbed masses: Theory and experiments. Sensors 2013, 13, 6089-6108. [CrossRef] [PubMed]

4. Sherrit, S.; Olazábal, V.; Sansiñena, J.M.; Bao, X.; Chang, Z.; Bar-Cohen, Y. The use of piezoelectric resonators for the characterization of mechanical properties of polymers. In Proceedings of the SPIE's 9th Annual International Symposium on Smart Structures and Materials, San Diego, CA, USA, 11 July 2002.

5. Ballato, A. Modeling piezoelectric and piezomagnetic devices and structures via equivalent networks. IEEE Trans. Ultrason. Ferroelectr. Freq. Control 2001, 48, 1189-1240. [CrossRef] [PubMed]

6. Marschner, U.; Datta, S.; Starke, E.; Fischer, W.; Flatau, A.B. Equivalent circuit of a piezomagnetic unimorph incorporating single-crystal Galfenol. IEEE Trans. Magn. 2014, 50, 1-4. [CrossRef]

7. Granstaff, V.E.; Martin, S.J. Characterization of a thickness-shear layers mode quartz resonator with multiple nonpiezoelectric layers. J. Appl. Phys. 1994, 75, 1319-1329. [CrossRef]

8. Mason, W.P. An electromechanical representation of a piezoelectric crystal used as a transducer. Proc. Inst. Radio Eng. 1935, 23, 1252-1263.

9. Germano, C.P. Flexure mode piezoelectric transducers. IEEE Trans. Audio Electroacoust. 1971, 19, 6-12. [CrossRef]

10. Bao, X.Q.; Varadan, V.K.; Varadan, V.V.; Howarth, T.R. Model of a bilaminar actuator for active acoustic control systems. J. Acoust. Soc. Am. 1990, 87, 1350-1352. [CrossRef]

11. Yang, Y.; Tang, L. Equivalent Circuit Modeling of Piezoelectric Energy Harvesters. J. Intel. Mater. Syst. Struct. 2009, 20, 2223-2235. [CrossRef]

12. Wang, H.; Tang, L.; Shan, X.; Xie, T.; Yang, Y. Modeling and performance evaluation of a piezoelectric energy harvester with segmented electrodes. Smart Struct. Syst. 2014, 14, 247-266. [CrossRef]

13. Tomikawa, Y.; Takano, T.; Umeda, H. Thin rotary and linear ultrasonic motors using a double-mode piezoelectric vibrator of the first longitudinal and second bending modes. Jpn. J. Appl. Phys. 1992, 31, 3073-3076. [CrossRef]

14. Bein, T.; Breitbach, E.J.; Uchino, K. A linear ultrasonic motor using the first longitudinal and the fourth bending mode. Smart Mater. Struct. 1997, 6, 619-627. [CrossRef] 
15. Zhai, B.; Lim, S.; Lee, K.; Dong, S.; Lu, P. A modified ultrasonic linear motor. Sensor Actuators A Phys. 2000, 86, 154-158. [CrossRef]

16. Park, T.; Kim, B.; Kim, M.; Uchino, K. Characteristics of the first longitudinal-fourth bending mode linear ultrasonic motors. Jpn. J. Appl. Phys. 2002, 41, 7139-7143. [CrossRef]

17. Rho, J.; Kim, B.; Lee, C.; Joo, H.; Jung, H. Design and characteristic analysis of L1B4 ultrasonic motor considering contact mechanism. IEEE Trans. Ultrason. Ferroelectr. Freq. Control 2005, 52, 2054-2064. [PubMed]

18. Dong, S.; Zhai, J. Equivalent circuit method for static and dynamic analysis of magnetoelectric laminated composites. Chin. Sci. Bull. 2008, 53, 2113-2123. [CrossRef]

19. Dong, S.; Li, J.; Viehland, D. Longitudinal and transverse magnetoelectric voltage number of magnetostrictive/piezoelectric laminate composite: theory. IEEE Trans Ultrason. Ferroelectr. Freq. Control 2003, 50, 1253-1261. [CrossRef] [PubMed]

20. Holland, R. Representation of dielectric, elastic, and piezoelectric losses by complex numbers. IEEE Trans Son. Ultrason. 1967, 14, 18-20. [CrossRef]

21. Uchino, K.; Zhuang, Y.; Ural, S.O. Loss determination methodology for a piezoelectric ceramic: New phenomenological theory and experimental proposals. J. Adv. Dielectr. 2011, 1, 17-31. [CrossRef]

22. Sherrit, S.; Leary, S.P.; Dolgin, B.P.; Bar-Cohen, Y. Comparison of the Mason and KLM equivalent circuits for piezoelectric resonators in the thickness mode. IEEE Ultrason. Symp. 1999, 2, 921-926.

23. Chen, Y.; Wen, Y.; Li, P. Characterization of dissipation factors in terms of piezoelectric equivalent circuit parameters. IEEE Trans Ultrason. Ferroelectr. Freq. Control 2006, 53, 2367-2375. [CrossRef] [PubMed]

24. Dong, X.; Majzoubi, M.; Choi, M.; Ma, Y.; Hu, M.; Jin, L.; Xu, Z.; Uchino, K. A new equivalent circuit for piezoelectrics with three losses and external loads. Sensor Actuator A Phys. 2017, 256, 77-83. [CrossRef]

25. Carfagni, M.; Lenzi, E.; Pierini, M. The loss factor as a measure of mechanical damping. Int. Soc. Opt. Eng. 1998, 1, 580-584.

26. Thomson, W.T.; Dahleh, M.D. Theory of Vibration with Application; Prentice Hall: Upper Saddle River, NJ, USA, 1998.

27. Montalvão, D.; Cláudio, R.A.L.D.; Ribeiro, A.M.R.; Duarte-Silva, J. Experimental measurement of the complex Young's modulus on a CFRP laminate considering the constant hysteretic damping model. Compos. Struct. 2013, 97, 91-98. [CrossRef]

28. Majzoubi, M.; Shekhani, H.N.; Bansal, A.; Hennig, E.; Scholehwar, T.; Uchino, K. Advanced methodology for measuring the extensive elastic compliance and mechanical loss directly in $\mathrm{k} 31$ mode piezoelectric ceramic plates. J. Appl. Phys. 2016, 120, 225113. [CrossRef]

29. Yuan, Y.; Du, H.; Xia, X.; Wong, Y. Analytical solutions to flexural vibration of slender piezoelectric multilayer cantilevers. Smart Mater. Struct. 2014, 23, 095005. [CrossRef]

30. Ballas, R.G. Piezoelectric Multilayer Beam Bending Actuators: Static and Dynamic Behavior and Aspects of Sensor Integration; Springer: Berlin, Germany, 2007.

31. Zhou, H.; Li, C.; Xuan, L.; Wei, J.; Zhao, J. Equivalent circuit method research of resonant magnetoelectric characteristic in magnetoelectric laminate composites using nonlinear magnetostrictive constitutive model. Smart Mater. Struct. 2011, 20, 035001. [CrossRef]

32. Berlincourt, D.A.; Curran, D.R.; Jaffe, H. Piezoelectric and Piezomagnetic Materials and Their Function in Transducers. In Physical Acoustics Principles and Methods; Volume 1-Part A; Mason, W.P., Ed.; Academic Press: New York, NY, USA; London, UK, 1964; pp. 233-250.

33. Colakoglu, M. Factors effecting internal damping in aluminum. J. Theor. Appl. Mech. 2004, 42, 95-105.

34. Cherif, R.; Chazot, J.; Atalla, N. Damping loss factor estimation of two-dimensional orthotropic structures from a displacement field measurement. J. Sound Vib. 2015, 356, 61-71. [CrossRef]

35. Ege, K.; Boncompagne, T.; Guyader, J.; Laulagnet, B. Experimental estimations of viscoelastic properties of multilayer damped plates in broad-band frequency range. arXiv 2012.

(C) 2018 by the authors. Licensee MDPI, Basel, Switzerland. This article is an open access article distributed under the terms and conditions of the Creative Commons Attribution (CC BY) license (http://creativecommons.org/licenses/by/4.0/). 